\title{
Barrett's esophagus and cardiac intestinal metaplasia: Two conditions within the same spectrum
}

\author{
Nicole White $\mathrm{BSC}^{1}$, Manal Gabril MD FRCPC MSc ${ }^{2}$, Gershon Ejeckam MD FRCPC ${ }^{3}$, Maria Mathews PhD ${ }^{4}$, \\ John Fardy MD FRCPC ${ }^{5}$, Fady Kamel ${ }^{1}$, Jules Doré PhD ${ }^{1}$, George M Yousef MD PhD FRCPC (Path) ${ }^{6,7}$
}

\begin{abstract}
N White, M Gabril, G Ejeckam, et al. Barrett's esophagus and cardiac intestinal metaplasia: Two conditions within the same spectrum. Can J Gastroenterol 2008;22(4):369-375.
\end{abstract}

BACKGROUND: Immunostaining for cytokeratin 7 (CK7) and cytokeratin 20 (CK20) has a characteristic pattern in Barrett's esophagus (BE), but reports regarding its sensitivity and specificity are inconsistent. Intestinal metaplasia of the gastric cardia (CIM) is histologically similar to BE, but with no abnormal endoscopic findings. OBJECTIVES: To evaluate the sensitivity and specificity of a semiquantitative CK7/CK20 immunostaining pattern for the diagnosis of $\mathrm{BE}$, and to further elucidate the pathogenesis of CIM.

METHODS: Tissues were examined by hematoxylin and eosin and periodic acid schiff/alcian blue stains, and then were immunostained with CK7 and CK20 antibodies. Correlations with other clinical parameters were statistically analyzed.

RESULTS: When values were revised based on follow-up data and auxiliary testing, all BE cases (100\%) displayed the characteristic BE CK7/CK20 immunostaining pattern, compared with 66\% of CIM cases. In the subgroup of patients who were endoscopically and immunohistochemistry-positive but histologically negative, all patients except for one had documented BE when clinical history, auxiliary testing and follow-up were evaluated. There were no statistically significant differences between BE and CIM regarding Helicobacter pylori infection or the type of metaplasia (complete versus incomplete). The sensitivity of the CK7/CK20 pattern reached $100 \%$ in the subgroup of CIM patients with a history of acid reflux. Of 26 cases of CIM where follow-up was available, four cases (15\%) progressed to BE, and one developed dysplasia. All four cases showed the $\mathrm{BE}$ pattern of $\mathrm{CK} 7 / \mathrm{CK} 20$ staining and were negative for $\mathrm{H}$ pylori infection.

CONCLUSIONS: A semiquantitative CK7/CK20 pattern can be used to confirm BE even in the absence of histological evidence. The subgroup of CIM with acid reflux may develop into BE and may need closer follow-up.

\section{L'œsophage de Barrett et la métaplasie intestinale du cardia : Deux problèmes faisant partie du même spectre}

\begin{abstract}
HISTORIQUE : L'immunomarquage à la cytokératine 7 (CK7) et à la cytokératine 20 (CK20) a un motif caractéristique dans l'œsophage de Barrett (OB), mais les rapports au sujet de sa sensibilité et de sa spécificité sont erratiques. La métaplasie intestinale du cardia gastrique (MIC) est similaire à l'OB du point de vue histologique, mais elle ne s'accompagne pas d'observations endoscopiques anormales.

OBJECTIFS : Évaluer la sensibilité et la spécificité d'un motif d'immunomarquage à CK7/CK20 semi-quantitatif pour diagnostiquer l'OB et mieux déterminer la pathogenèse de la MIC.

MÉTHODOLOGIE : On a examiné les tissus par hématoxyline et éosine et par réaction à l'acide périodique Schiff /Bleu Alcian, puis on les a immunomarqués par des anticorps à la CK7 et la CK20. Les corrélations avec d'autres paramètres cliniques ont fait l'objet d'analyses statistiques. RÉSULTATS : Lorsqu'on a examiné les valeurs d'après des données de suivi et des tests auxiliaires, tous les cas d'OB (100\%) ont affiché le motif d'immunomarquage à CK7/CK20 caractéristique de l'OB, par rapport à $66 \%$ des cas de MIC. Dans le sous-groupe de patients qui étaient positifs d'après l'endoscopie et l'immunohistochimie mais négatifs d'après l'histologie, tous les patients, sauf un, présentaient un $\mathrm{OB}$ documenté après l'évaluation des antécédents cliniques, des tests auxiliaires et du suivi. On ne remarquait aucune différence statistiquement significative entre l'OB et la MIC pour ce qui est de l'infection par Helicobacter pylori ou du type de métaplasie (complète ou incomplète). La sensibilité du motif à CK7/CK20 atteignait $100 \%$ dans le sous-groupe de patients atteints d'une MIC ayant des antécédents de reflux acide. Des 26 cas de MIC pour lesquels on possédait des données de suivi, quatre cas (15\%) se sont détériorés en $\mathrm{OB}$, et un, en dysplasie. Les quatre cas présentaient le motif de coloration à CK7/CK20 et étaient négatifs à l'infection par $H$ pylori. CONCLUSIONS : Un motif à CK7/CK20 semi-quantitatif peut permettre de confirmer un $\mathrm{OB}$, même en l'absence de données histologiques. Le sous-groupe de MIC avec reflux acide peut se détériorer en $\mathrm{OB}$ et exiger un suivi plus étroit.
\end{abstract}

Key Words: Barrett's esophagus; Cardiac intestinal metaplasia; CK7; CK20; Dysplasia; H pylori

B arrett's esophagus (BE) is an acquired condition in which the squamous epithelium at the distal esophagus is replaced by intestinal epithelium with goblet cells (1). This metaplastic process commonly develops from mucosal injuries as a result of gastroesophageal reflux disease (2). BE is a major risk factor for

the development of esophageal adenocarcinoma (3), because approximately $0.5 \%$ of patients with BE develop this malignancy each year (4).

The normal histology of the squamocolumnar junction (SCJ) and, in particular, the nature of the cardiac mucosa and

${ }^{1}$ BioMedical Sciences, Memorial University, St John's, Newfoundland; ${ }^{2}$ Discipline of Pathology, London Health Sciences Centre, London, Ontario; ${ }^{3}$ Discipline of Pathology, Eastern Health; ${ }^{4}$ Division of Community Health and Humanities, Memorial University; ${ }^{5}$ Gastroenterology Unit, Eastern Health, St John's, Newfoundland; ${ }^{6}$ Department of Laboratory Medicine; ${ }^{7}$ Keenan Research Centre of the Li Ka Shing Knowledge Institute, St Michael's Hospital, Toronto, Ontario

Correspondence: Dr George M Yousef, Department of Laboratory Medicine, St Michael's Hospital, 30 Bond Street, Toronto, Ontario

M5B 1W8. Telephone 416-864-6060 ext 6129, fax 416-864-5648, e-mail yousefg@smh.toronto.on.ca

Received for publication October 11, 2007. Accepted January 7, 2008 
whether it represents a normal anatomical segment or an acquired condition, remains in dispute (5). Both cardiac intestinal metaplasia (CIM) and BE are histologically identical, characterized by the presence of intestinal metaplasia (IM) with goblet cells. The two conditions are differentiated only by the finding of endoscopically visible tongues of columnar mucosa of any length, which would qualify the lesion as BE, while endoscopically negative individuals are diagnosed with CIM $(5,6)$. Only a small proportion of patients with BE present with endoscopically obvious long segments of columnar epithelium (longer than $3 \mathrm{~cm}$ ) above the gastroesophageal junction (GEJ) (7,8). Short segment BE (shorter than $3 \mathrm{~cm}$ in length), and more recently, ultrashort segment BE are more difficult to recognize by endoscopy, potentially being confused with CIM (9). Several attempts have been made to differentiate reliably between these conditions based on their etiology and the type of mucin produced $(10,11)$, but the results were not consistent.

The significance of CIM is not well understood. Some suggest that it is linked to Helicobacter pylori infection $(12,13)$, while others associate it with acid reflux $(5,14,15)$. Another study suggests that patients with short segment BE have a higher risk for developing dysplasia than patients with CIM (16).

Cytokeratin 7 (CK7) and cytokeratin 20 (CK20) are intermediate-sized cytoplasmic structural proteins that form a major component of the cytoskeleton of human cells (17). CK7, a marker of ductal differentiation, is not expressed in the normal epithelium of the gastrointestinal tract or esophagus, while CK20, a marker of intestinal differentiation, is normally expressed in the colon and small intestine but is limited to the surface foveolar epithelium in the stomach (5). Ormbsy et al (18) described a distinctive CK7/CK20 immunostaining pattern in patients with $\mathrm{BE}$ that is highly sensitive and specific. The immunostaining pattern has a strong, diffuse CK7 staining of the surface and glandular epithelium, and weak CK20 staining of the superficial epithelium (18). While these results were confirmed by later reports $(1,19)$, they were not reproducible by others $(3,20)$.

The purpose of the present study was to evaluate the sensitivity and specificity of a semiquantitative CK7/CK20 immunostaining pattern for the diagnosis of BE. In addition, we attempt to explore the pathogenesis of CIM and its relationship with BE by comparing the two conditions in terms of CK7/CK20 immunostaining pattern, type of IM, associated $H$ pylori infection, acid reflux, and history of anemia and malignancy, and by following up on some CIM cases.

\section{METHODS}

\section{Patient selection and endoscopy}

Biopsies of the SCJ from patients who underwent upper gastrointestinal endoscopy and biopsy at Eastern Health (St John's, Newfoundland) were retrospectively examined. Successive biopsies were selected for pathology evaluation, immunohistochemistry (IHC) staining and analysis if the specimen was optimal, with full clinical and endoscopic data, as described below. Endoscopically, the GEJ was identified by the junction of the tubular esophagus with the most proximal gastric folds. Histologically, biopsies were obtained from the SCJ (minimum of three biopsies per patient). To ensure that biopsies were representative of the SCJ, specimens that did not contain both squamous and glandular epithelium were excluded. Suboptimal biopsies (eg, tiny fragmented tissue, lack of superficial or deep epithelial components) were also excluded. Normal controls included SCJ biopsies without IM, biopsies from the gastric antrum with IM and normal gastric mucosa. Histological slides were reviewed by two pathologists.

Patients' clinical information (including history of acid reflux) determined by documented history and/or investigations, was obtained from clinical charts. $\mathrm{H}$ pylori infection was assessed histologically. Specimens were identified as having complete or incomplete metaplasia based on periodic acidSchiff (PAS) and alcian blue (AB) staining (see below). All protocols were approved by the Human Investigation Committee at Memorial University (St John's, Newfoundland).

\section{Histology and definitions}

Slides were stained with hemotoxylin and eosin using standard techniques. For case definitions, the criteria of the American College of Gastroenterology and its Practice Parameters Committee (21) were used, which have also been used by recent studies $(6,22)$. The CIM group was defined as patients with no endoscopic evidence of BE, and a biopsy of the SCJ that showed IM with goblet cells. Presence of the gastric cardia was confirmed histologically by the presence of branching mucous glands without parietal cells. Cases of BE were defined as the presence of tongues of gastric mucosa of any length (or irregularities of the Z-line) in the lower esophagus and the presence of IM with goblet cells in the histology biopsy of the SCJ. Normal controls were defined as biopsies from the SCJ with negative endoscopy and no evidence of IM on histology. IM of the gastric antrum was defined as the presence of IM with goblet cells in a histologically confirmed biopsy from the antrum.

\section{Immunohistochemical staining for CK7 and CK20}

Paraffin blocks were sectioned at a thickness of $4 \mu \mathrm{m}$, mounted on slides and dried overnight. Sections were deparaffinized in xylene and rehydrated through decreasing graded alcohols. Slides were immunostained using the Ventana Benchmark instrument (Ventana Medical Systems Inc, USA) with monoclonal antibodies for CK7 (clone OV-TL 12/30, Dako Canada, Canada; dilution 1:400) and CK20 (clone Ks20.8, Cell Marque, USA; prediluted by the manufacturer). Antigen retrieval for the CK7 antibody utilized digestion with protease 1 for $4 \mathrm{~min}$, while a heat-induced epitope retrieval using cell conditioner 1 (tris/EDTA/borate buffer, $\mathrm{pH}$ 8.0) was performed for the CK20 antibody. Immune complex was visualized by incubating with diaminobenzidine, and sections were counterstained with hemotoxylin.

All slides were reviewed and scored independently by two pathologists. Disagreements were settled by revised assessment by both pathologists. A semiquantitative assessment was used to define the BE CK7/CK20 immunostaining pattern. Immunoreactivity was assessed as both percentage positivity of slide surface area (negative, $0 \%$ to $5 \%$; focal, $6 \%$ to $25 \%$; intermediate, $26 \%$ to $50 \%$ ); and diffuse, $50 \%$ to $100 \%$ ) and intensity of staining (weak, moderate or strong). Cases were considered positive for the BE CK7/CK20 immunostaining pattern if strong, diffuse CK20 staining was observed in the surface epithelium and superficial glands, and strong, diffuse CK7 staining was seen in both the superficial and deep glands (23) (Figure 1). 

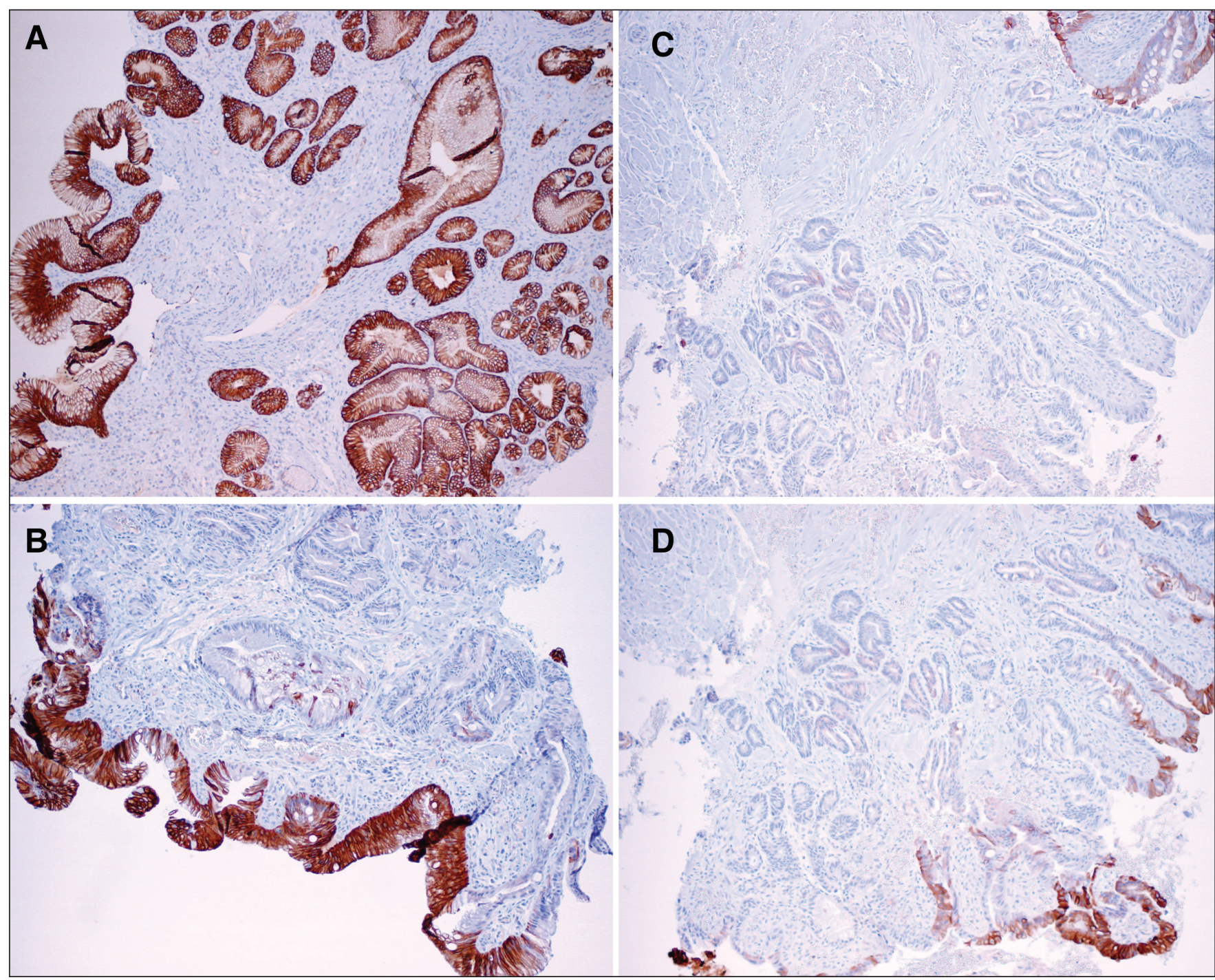

Figure 1) Immunohistochemical staining for cytokeratin 7 (CK7) and cytokeratin 20 (CK20). The Barrett's esophagus pattern is characterized by strong, diffuse CK7 staining in both the superficial and deep glands (A) and strong, diffuse CK20 staining in the surface epithelium and superficial glands (B). A negative Barrett's esophagus pattern shows no immunoreactivity for CK7 (C) and no or focal weak reactivity for CK20 (D)

\section{PAS/AB staining}

Slides were hydrated, stained with $\mathrm{AB}$ at a $\mathrm{pH}$ of 2.5 for 5 min and washed well with water. Slides were then incubated in $1 \%$ periodic acid stain for $5 \mathrm{~min}$, washed in distilled water, incubated in Schiff reagent for 8 min and washed in running tap water for $10 \mathrm{~min}$. Slides were then dehydrated, cleared and mounted.

Complete IM was defined as mucosal epithelium of the small intestinal type with mucin-secreting goblet cells, which stain blue by PAS/AB staining, and nonsecretory absorptive cells with brush border, which do not stain (Figure 2A) (6). Incomplete IM has mucin-secreting goblet cells that stain blue by PAS/AB staining, and secretory columnar mucus cells that stain red or purple (Figure 2B) (6).

\section{Statistical analysis}

The statistical significance between groups was assessed by $\chi^{2}$ analysis and, where appropriate, Fisher's exact test. For each variable, the following comparisons were made: $\mathrm{BE}$ with controls, BE with CIM and CIM with controls. Differences between groups were considered significant when $\mathrm{P}<0.05$. Sensitivity, specificity, and positive and negative predictive values were computed from a standard $2 \times 2$ table (24). SPSS 13.0 for Windows (SPSS Inc, USA) was used for all statistical analyses.

\section{RESULTS}

Of 144 consecutive patients who underwent upper gastrointestinal endoscopy and biopsy, 19 cases were excluded because they contained only squamous or glandular epithelium and could not be verified as a true representation of the SCJ. Another 22 cases were excluded because they were suboptimal for evaluation (ie, very fragmented biopsies). The final sample group comprised 103 cases: 39 with BE, 35 with CIM and 29 normal SCJ controls. Additionally, 25 biopsies from the gastric antrum with IM, 15 normal gastric mucosa (away from the SCJ) and 32 biopsies of normal esophagi, were included as controls. 


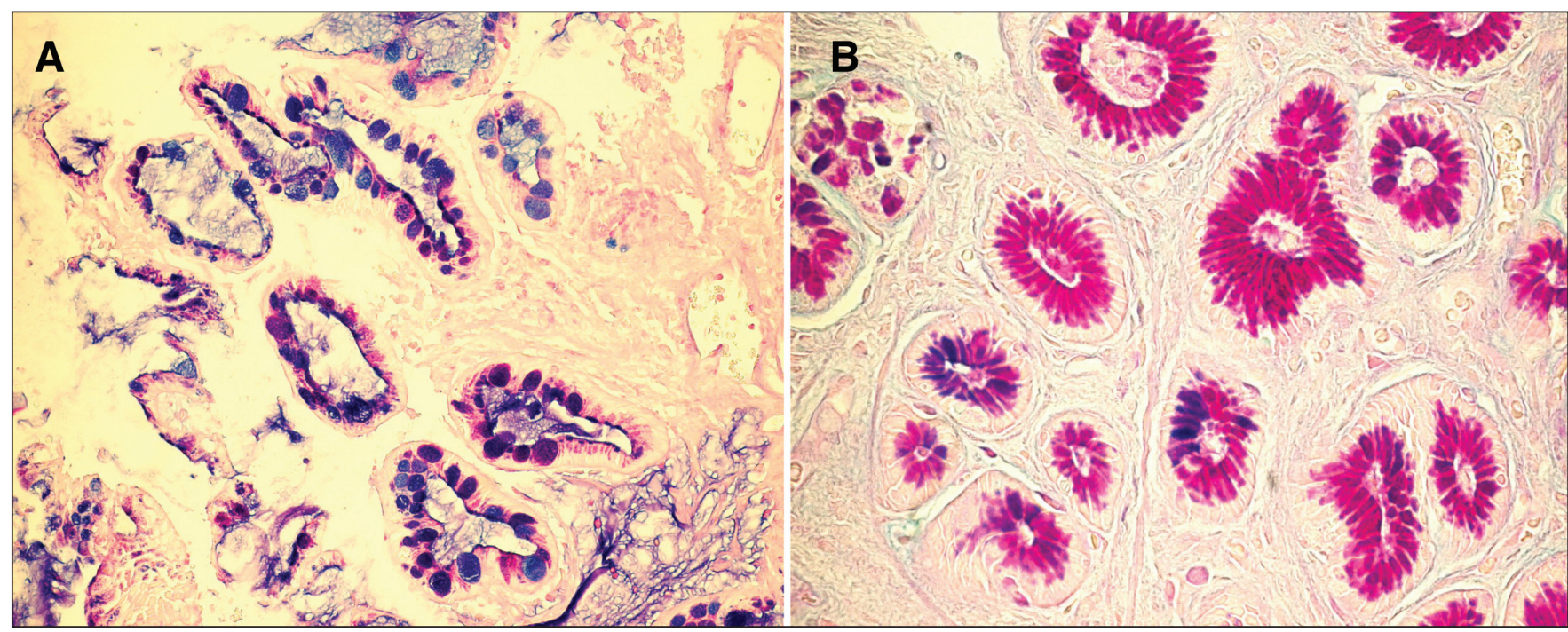

Figure 2) Periodic acid-Schiff (PAS) and alcian blue (AB) staining. A Complete intestinal metaplasia, showing mucosal epithelium of the small intestinal type with mucin-secreting goblet cells (stained blue) and nonsecretory absorptive cells with brush border (do not stain). B Incomplete intestinal metaplasia, showing mucin-secreting goblet cells (stained blue) and secretory columnar mucous cells (stained red or purple)

TABLE 1

Distribution of characteristics among different patient groups

\begin{tabular}{|c|c|c|c|c|c|c|}
\hline \multirow[b]{2}{*}{ Characteristic } & \multicolumn{3}{|c|}{ Group, n (\%) } & \multirow[b]{2}{*}{$\mathbf{P}^{*}$} & \multirow[b]{2}{*}{$\mathbf{P}^{\dagger}$} & \multirow[b]{2}{*}{$P^{\ddagger}$} \\
\hline & Control & CIM & BE & & & \\
\hline \multicolumn{7}{|l|}{ Age } \\
\hline$\geq 65 \mathrm{y}$ & $9(31.0)$ & $11(31.4)$ & $14(35.9)$ & & & \\
\hline \multicolumn{7}{|l|}{ Sex } \\
\hline Male & $11(37.9)$ & $20(57.1)$ & $28(71.8)$ & 0.126 & 0.005 & 0.187 \\
\hline \multicolumn{7}{|l|}{ Acid reflux } \\
\hline Positive & $11(47.8)$ & $12(44.4)$ & $28(71.8)$ & 0.811 & 0.059 & 0.025 \\
\hline Negative & $12(52.2)$ & $15(55.6)$ & $11(28.2)$ & & & \\
\hline \multicolumn{7}{|c|}{ Helicobacter pylori infection } \\
\hline Positive & $3(10.3)$ & $6(17.1)$ & $2(5.1)$ & 0.436 & $0.644 \S$ & $0.097 \S$ \\
\hline \multicolumn{7}{|l|}{ History of anemia } \\
\hline Positive & $4(13.8)$ & $2(7.4)$ & $4(10.3)$ & $0.671^{\S}$ & 0.654 & $1.00 \S$ \\
\hline Negative & $25(86.2)$ & $25(92.6)$ & $35(89.7)$ & & & \\
\hline \multicolumn{7}{|l|}{ Gastric cancer" } \\
\hline Positive & $2(6.9)$ & $2(7.4)$ & $13(33.3)$ & $1.00 \S$ & $0.016 \S$ & $0.017 \S$ \\
\hline \multicolumn{7}{|l|}{ Gastric lesion ${ }^{* *}$} \\
\hline Positive & $3(10.3)$ & $5(18.5)$ & $13(33.3)$ & 0.382 & 0.027 & 0.184 \\
\hline \multicolumn{7}{|c|}{ Gastrointestinal tumour ${ }^{\dagger \dagger}$} \\
\hline Positive & $7(24.1)$ & $4(14.8)$ & $8(20.5)$ & 0.380 & 0.721 & 0.555 \\
\hline
\end{tabular}

${ }^{*}$ Control group versus cardiac intestinal metaplasia (CIM) group; ${ }^{\dagger}$ Control group versus Barrrett's esophagus (BE) group; $\neq_{C}$ IM group versus BE group; $\$$ Fisher's exact test; ${ }^{\top}$ Personal past history of gastric cancer or premalignant condition (adenomatous polyps); **Past or family history of any gastric lesion including cancer, premalignant condition or benign polyp; t†Past or family history of any gastrointestinal malignant or premalignant condition. N/A Not applicable

Table 1 shows the distribution of characteristics among the control, CIM and BE groups. Patient ages ranged from 20 to 89 years, with a mean age of 57 years. Table 2 shows the
CK7/CK20 immunostaining pattern among different groups. All BE cases (100\%) displayed the characteristic BE CK7/CK20 immunostaining pattern. Only 66\% of the CIM 
TABLE 2

Barrett's esophagus (BE) cytokeratin 7 and cytokeratin 20 immunostaining pattern among different patient groups

\begin{tabular}{llcc}
\hline & \multicolumn{3}{c}{ BE pattern*, n (\%) } \\
\hline Group & Positive & Negative & Total \\
\hline BE $^{\dagger}$ & $39(100)$ & 0 & 39 \\
Cardiac intestinal metaplasia $^{\dagger}$ & $23(66)$ & $12(34)$ & 35 \\
Cardiac intestinal metaplasia with $^{\text {acid reflux }}{ }^{\ddagger}$ & $12(100)$ & 0 & 12 \\
Gastric antral metaplasia $^{\dagger}$ & & & \\
Normal stomach $^{\dagger}$ & 0 & $25(100)$ & 25 \\
Normal esophagus $^{\dagger}$ & 0 & $15(100)$ & 15 \\
\hline
\end{tabular}

*Positive cases are defined as having the characteristic BE immunostaining pattern as described in the methods section; ${ }^{\dagger}$ For category definitions, see the methods section; ${ }^{\ddagger}$ Defined as the presence of intestinal metaplasia with goblet cells in endoscopy-negative individuals with a history of acid reflux

biopsies displayed this pattern. When the subgroup of CIM patients with a history of acid reflux was evaluated for the $\mathrm{BE}$ staining pattern, $100 \%$ of cases were positive. None of the biopsies with IM of the antrum, normal stomach or esophagus, showed the BE CK7/CK20 immunostaining pattern.

The sensitivity and specificity of the CK7/CK20 immunostaining pattern for BE and CIM patients is displayed in Table 3. Sensitivity was higher in the BE group than in the CIM group (100\% versus $66 \%$, respectively), while the specificity was $80 \%$ for both groups. The positive and negative predictive values ( $83 \%$ and $100 \%$, respectively) in the BE group were higher than those in the CIM group (74\% and 73\%, respectively). In the subgroup of CIM patients with acid reflux, the sensitivity increased to $100 \%$ (Table 3 ).

An interesting subgroup of eight patients was analyzed further. In this subgroup, endoscopic results were positive (ie, presence of tongues of gastric mucosa extending to a variable length into the proximal esophagus), and showed the CK7/CK20 BE immunostaining pattern on IHC, but they all lacked evidence of IM by histological assessment. When reevaluated using auxiliary testing and clinical data, two of these cases showed focal IM by PAS/AB staining. Out of the remaining six cases, three showed IM in a previous biopsy, and two showed IM in a follow-up biopsy after one to two years. There was no follow-up available for the remaining case. These findings suggest that in an endoscopically positive individual, the CK7/CK20 immunostaining pattern might be a more sensitive indicator of $\mathrm{BE}$ than histological identification of IM.

In an attempt to elucidate the pathogenesis of CIM and its relationship with $\mathrm{BE}$, the two conditions were compared with each other and with the control group with respect to different characteristics (Table 1). There was no significant difference between these groups regarding age, $H$ pylori infection or history of anemia. There was a statistically significant male predominance in the BE group when compared with controls $(\mathrm{P}=0.005)$. There was a statistically significant difference in the presence of acid reflux (documented by the presence of symptoms, patient recall and/or clinical investigations) between the $\mathrm{BE}$ and the CIM groups $(\mathrm{P}=0.025)$. A similar trend was seen when the $\mathrm{BE}$ and control groups were compared, but this value did not reach statistical significance. There was a statistically significant predominance of a history of gastric cancer
TABLE 3

Sensitivity, specificity, and positive and negative predictive values of the Barrett's esophagus (BE) cytokeratin 7 and cytokeratin 20 immunostaining pattern in cases of BE and cardiac intestinal metaplasia (CIM)

\begin{tabular}{|c|c|c|c|}
\hline Variable & $\mathrm{BE}^{*}$ & $\mathrm{CIM}^{*}$ & $\mathrm{CIM}+\mathrm{acid}^{\dagger}$ \\
\hline Sensitivity ${ }^{\ddagger}, \%$ & 100 & 66 & 100 \\
\hline Specificity ${ }^{\ddagger}, \%$ & 80 & 80 & 73 \\
\hline Positive predictive value ${ }^{\ddagger}, \%$ & 83 & 74 & 73 \\
\hline Negative predictive value ${ }^{\ddagger}, \%$ & 100 & 73 & 100 \\
\hline
\end{tabular}

${ }^{*}$ For case definitions, please see the methods section; ${ }^{\dagger}$ The subgroup of CIM patients with a history of acid reflux; ${ }^{\ddagger}$ Values are computed from a standard $2 \times 2$ table (24)

or premalignant condition in the $\mathrm{BE}$ group compared with the CIM group $(\mathrm{P}=0.017)$ and the control group $(\mathrm{P}=0.016)$. Also, the BE group had more patients with a past or family history of gastric lesions than the control group $(\mathrm{P}=0.027)$.

The subgroup of CIM patients with a history of acid reflux showed $100 \%$ positivity for the CK7/CK20 staining pattern (Table 2). On the other hand, in the subgroup of CIM with positive CK7/CK20 immunostaining pattern, the frequency of acid reflux was higher than the total CIM population (100\% versus $34 \%$ ) (data not shown).

Of 26 cases of CIM where follow-up endoscopy was available, four cases $(15 \%)$ progressed to $\mathrm{BE}$ within two years, and one patient developed dysplasia. All four cases showed a positive BE pattern of CK7/CK20 immunostaining and all were negative for $\mathrm{H}$ pylori infection. Three of these patients were male and one was female. Two patients had incomplete and two had complete IM (data not shown).

\section{DISCUSSION}

Our results of a semiquantitative assessment show that the BE pattern of immunostaining is 100\% sensitive and $80 \%$ specific in patients with $\mathrm{BE}$, but this pattern appears to be less sensitive (66\%) for CIM. These results are similar to some previous reports $(5,25)$, but were not always reproducible. The apparent discrepancy between studies may be due to a number of factors, including inaccurate visualization of short segment $\mathrm{BE}$ on endoscopy, interobserver variability, tissue fixation differences, and immunohistochemical staining differences (eg, antigen retrieval methods (25). Another important factor is the anatomical location from which the biopsy was taken, because biopsies obtained distal to the cardia have a significantly lower likelihood of showing a BE pattern.

To our knowledge, the present report is the first to provide evidence that the BE immunostaining pattern is more sensitive than histology in detecting BE. Follow-up of histologically negative specimens that were positive by endoscopy and immunostaining showed that IM was documented in these patients in a follow-up biopsy or by auxiliary testing. Our findings suggest that a semiquantitative CK7/CK20 immunostaining pattern can be used to confirm BE, even when goblet cells are not identifiable histologically. A larger scale study should be performed to confirm these findings.

The prevalence of CIM in the general population and its clinical significance has not yet been confirmed. Polkowski et al (6), found IM in $12 \%$ of their normal study population. Their study sample, however, should not be considered a 
representation of a 'normal' population because it consisted mainly of patients who underwent gastroesophagectomy resection for cancer, which is a population in which we expect to see more of the metaplasia-dysplasia axis in the surrounding tissues. Others suggest that CIM represents a response to stressful stimuli. The nature of these stimuli could be acid reflux or other etiologies such as $H$ pylori infection $(12,13)$.

The relationship between BE and IM of the gastric cardia is still a matter of dispute (5). Reports have tried to differentiate the two conditions based on the staining patterns, but results are inconsistent. Another differentiating factor that has been tested is the type of IM, which can be either incomplete or complete. DeMeester et al (5), suggested that in patients with reflux as the etiology for their CIM, IM tends to be incomplete (similar to that of BE). In contrast, CIM secondary to $\mathrm{H}$ pylori infection tends to produce complete IM. Incomplete IM was found to be associated with an increased risk for cancer (26) and is considered a premalignant lesion in the distal stomach $(27,28)$. Similarly, incomplete IM was found to be associated with adenocarcinoma of the esophagus, arising within a background of BE (29). Our findings did not show a significant difference in the type of IM (complete versus incomplete) between CIM and BE $(\mathrm{P}=0.288)$, although there is a comparable trend toward incomplete IM in both conditions (Table 1). This is contradictory to a previous report (6), likely due to differences in sample size or the population selection bias.

Based on our findings, we hypothesize that CIM represents a response to stressful stimuli that might be either acid reflux or $H$ pylori infection. Our results provide several lines of evidence that BE and the subgroup of CIM with a history of acid reflux are two conditions within the same spectrum. This subset can possibly be identified by the CK7/CK20 immunostaining pattern, and is a precursor of BE. Similar to previous reports $(5,19)$, both conditions show considerable overlap of a specific CK7/CK20 immunostaining pattern that is not seen in other normal anatomical regions or IM of other parts of the stomach (Table 2). In the subgroup of CIM patients with acid reflux, the sensitivity of the BE pattern of IHC increased to $100 \%$ (compared with $66 \%$ in the total CIM population). In addition, there are no statistically significant differences between the two conditions regarding other parameters, such as the type of IM, associated $H$ pylori infection, acid reflux history, history of anemia and malignancy. Moreover, of 26 cases of CIM where follow-up endoscopy was available, four cases

\section{REFERENCES}

1. Sarbia M, Donner A, Franke C, Gabbert HE. Distinction between intestinal metaplasia in the cardia and in Barrett's esophagus: The role of histology and immunohistochemistry. Hum Pathol 2004;35:371-6.

2. Terano A, Morita K, Nakamura T, Ohkura Y, Ono Y, Fujimori T. Barrett's esophagus. J Gastroenterol 2002;37:685-90.

3. El-Zimaity HM, Graham DY. Cytokeratin subsets for distinguishing Barrett's esophagus from intestinal metaplasia in the cardia using endoscopic biopsy specimens. Am J Gastroenterol 2001;96:1378-82.

4. Shaheen NJ, Crosby MA, Bozymski EM, Sandler RS. Is there publication bias in the reporting of cancer risk in Barrett's esophagus? Gastroenterology 2000;119:333-8.

5. DeMeester SR, Wickramasinghe KS, Lord RV, et al. Cytokeratin and DAS-1 immunostaining reveal similarities among cardiac mucosa, CIM, and Barrett's esophagus. Am J Gastroenterol 2002;97:2514-23.
(15\%) progressed to BE within two years. All four cases showed a positive BE pattern of CK7/CK20 immunostaining, and all were negative for $H$ pylori infection. Three of these patients were male and one was female. Interestingly, there is a documented male predominance of adenocarcinoma of the esophagus (30).

Our findings that CIM is not necessarily linked to $H$ pylori infection (Table 1) is supported by recent epidemiological evidence. H pylori is a known risk factor for the development of gastritis and IM. Worldwide, the incidence of gastric cancer is declining, most likely due to the decrease of infection by $\mathrm{H}$ pylori $(31,32)$. An opposite trend is seen in the cardia, with increasing incidence of cardiac adenocarcinoma, despite decreasing H pylori infection.

Our hypothesis, if proven by larger scale studies, could resolve the apparent contradiction in previous studies. El-Serag et al (33) and Goldblum et al (34) suggest that gastroesophageal reflux disease is not a risk factor for CIM. On the other hand, Oberg et al (35) reported the development of cardiac mucosa (with some proceeding to IM) in the proximal esophagus after esophagectomy, suggesting that this is an acquired condition related to acid exposure. Interestingly, Sharma et al (16) found that there was a higher prevalence and incidence of dysplasia in their short segment BE group than in their CIM group ( $11.3 \%$ versus $4.6 \%$, respectively). These data support our hypothesis that the development of BE is a progression from CIM to BE, then to dysplasia. Further studies should be performed to determine whether the presence or absence of a BE pattern of CK7/CK20 immunostaining could predict progression to dysplasia or carcinoma, as previously suggested (25).

\section{CONCLUSIONS}

Our findings suggest that the CK7/CK20 immunostaining pattern is sensitive and specific for $\mathrm{BE}$, and that a semiquantitative CK7/CK20 immunostaining pattern can be used to confirm BE, even when goblet cells are not histologically identified. In addition, we hypothesize that CIM represents a response to stressful stimuli such as acid reflux and $H$ pylori infection. The semiquantitative CK7/CK20 immunostaining pattern can help to subgroup CIM into acid-related and nonacid-related groups. The former subgroup might represent an earlier 'phase' of BE that requires less rigorous follow-up than BE patients, but yet more than CIM patients who currently have no follow-up.
6. Polkowski W, van Lanschot JJ, ten Kate FJ, et al. Intestinal and pancreatic metaplasia at the esophagogastric junction in patients without Barrett's esophagus. Am J Gastroenterol 2000;95:617-25.

7. Cameron AJ, Lomboy CT. Barrett's ssophagus: Age, prevalence, and extent of columnar epithelium. Gastroenterology 1992;103:1241-5.

8. Sharma P, Morales TG, Bhattacharyya A, Garewal HS, Sampliner RE. Dysplasia in short-segment Barrett's esophagus: A prospective 3-year follow-up. Am J Gastroenterol 1997;92:2012-6.

9. Spechler SJ. Clinical practice. Barrett's esophagus. N Engl J Med 2002;346:836-42.

10. Reis CA, David L, Correa P, et al. Intestinal metaplasia of human stomach displays distinct patterns of mucin (MUC1, MUC2, MUC5AC, and MUC6) expression. Cancer Res 1999;59:1003-7.

11. Silva E, Teixeira A, David L, et al. Mucins as key molecules for the classification of intestinal metaplasia of the stomach. Virchows Arch 2002;440:311-7. 
12. Morales TG, Sampliner RE, Bhattacharyya A. Intestinal metaplasia of the gastric cardia. Am J Gastroenterol 1997;92:414-8.

13. Goldblum JR, Vicari JJ, Falk GW, et al. Inflammation and intestina metaplasia of the gastric cardia: The role of gastroesophageal reflux and H. Pylori infection. Gastroenterology 1998;114:633-9.

14. Odze R. Cytokeratin 7/20 immunostaining: Barrett's oesophagus or gastric intestinal metaplasia? Lancet 2002;359:1711-3.

15. Csendes A, Smok G, Quiroz J, et al. Clinical, endoscopic, and functional studies in 408 patients with Barrett's esophagus, compared to 174 cases of intestinal metaplasia of the cardia. Am J Gastroenterol 2002;97:554-60.

16. Sharma P, Weston AP, Morales T, Topalovski M, Mayo MS, Sampliner RE. Relative risk of dysplasia for patients with intestinal metaplasia in the distal oesophagus and in the gastric cardia. Gut 2000;46:9-13

17. Moll R, Franke WW, Schiller DL, Geiger B, Krepler R. The catalog of human cytokeratins: Patterns of expression in normal epithelia, tumors and cultured cells. Cell 1982;31:11-24.

18. Ormsby AH, Goldblum JR, Rice TW, et al. Cytokeratin subsets can reliably distinguish Barrett's esophagus from intestinal metaplasia of the stomach. Hum Pathol 1999;30:288-94.

19. Glickman JN, Wang H, Das KM, et al. Phenotype of Barrett's esophagus and intestinal metaplasia of the distal esophagus and gastroesophageal junction: An immunohistochemical study of cytokeratins 7 and 20, Das-1 and 45 MI. Am J Surg Pathol 2001;25:87-94.

20. Wallner B, Sylvan A, Janunger KG, Bozoky B, Stenling R. Immunohistochemical markers for Barrett's esophagus and associations to esophageal Z-Line appearance. Scand J Gastroenterol 2001;36:910-5.

21. Sampliner RE. Practice guidelines on the diagnosis, surveillance, and therapy of Barrett's esophagus. The Practice Parameters Committee of the American College of Gastroenterology. Am J Gastroenterol 1998;93:1028-32.

22. Terano A, Morita K, Nakamura T, Ohkura Y, Ono Y, Fujimori T. Barrett's esophagus. J Gastroenterol 2002;37:685-90.
23. Ormsby AH, Vaezi MF, Richter JE, et al. Cytokeratin immunoreactivity patterns in the diagnosis of short-segment Barrett's esophagus. Gastroenterology 2000;119:683-90.

24. Hennekens C, Buring JE. Screening. In: Mayrent S, ed. Epidemiology in Medicine. Boston/Toronto: Little, Brown and Company, 1987:327-47.

25. Mohammed IA, Streutker CJ, Riddell RH. Utilization of cytokeratins 7 and 20 does not differentiate between Barrett's esophagus and gastric cardiac intestinal metaplasia. Mod Pathol 2002;15:611-6.

26. Filipe MI, Munoz N, Matko I, et al. Intestinal metaplasia types and the risk of gastric cancer: A cohort study in Slovenia. Int J Cancer 1994;57:324-9.

27. Jass JR. Role of intestinal metaplasia in the histogenesis of gastric carcinoma. J Clin Pathol 1980;33:801-10.

28. Kato Y, Kitagawa T, Yanagisawa A, et al. Site-dependent development of complete and incomplete intestinal metaplasia types in the human stomach. Jpn J Cancer Res 1992;83:178-83.

29. Jass JR. Mucin histochemistry of the columnar epithelium of the oesophagus: A retrospective study. J Clin Pathol 1981;34:866-70.

30. Streitz JM Jr, Ellis FH Jr, Gibb SP, Balogh K, Watkins E Jr. Adenocarcinoma in Barrett's esophagus. A clinicopathologic study of 65 cases. Ann Surg 1991;213:122-5.

31. Parsonnet J. The incidence of Helicobacter pylori infection. Aliment Pharmacol Ther 1995;9(Suppl 2):45-51.

32. Banatvala N, Mayo K, Megraud F, Jennings R, Deeks JJ, Feldman RA. The cohort effect and Helicobacter pylori. J Infect Dis 1993;168:219-21.

33. El-Serag HB, Sonnenberg A, Jamal MM, Kunkel D, Crooks L, Feddersen RM. Characteristics of intestinal metaplasia in the gastric cardia. Am J Gastroenterol 1999;94:622-7.

34. Goldblum JR, Richter JE, Vaezi M, Falk GW, Rice TW, Peek RM. Helicobacter pylori infection, not gastroesophageal reflux, is the major cause of inflammation and intestinal metaplasia of gastric cardiac mucosa. Am J Gastroenterol 2002;97:302-11.

35. Oberg S, Johansson J, Wenner J, Walther B. Metaplastic columnar mucosa in the cervical esophagus after esophagectomy. Ann Surg 2002;235:338-45. 


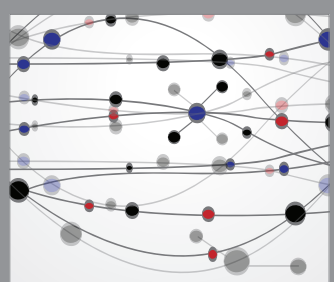

The Scientific World Journal
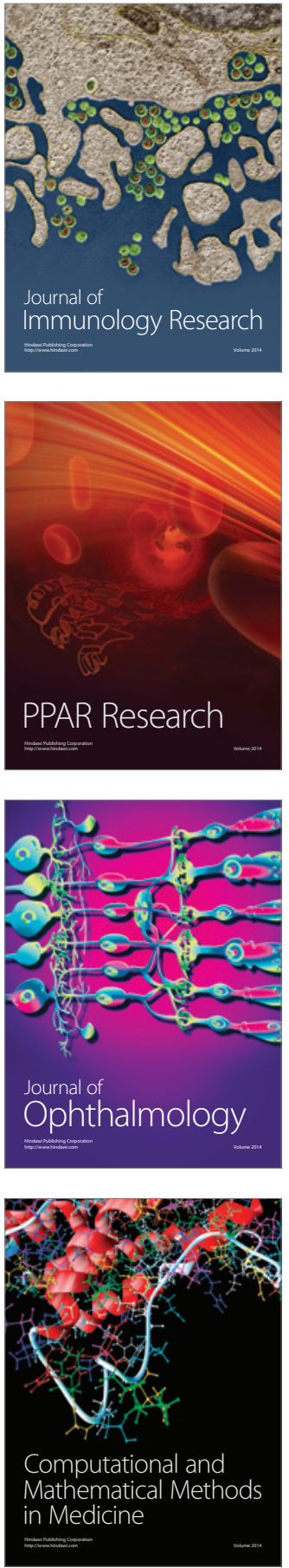

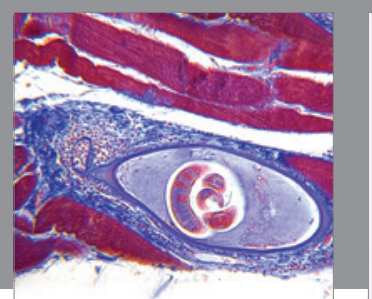

Gastroenterology Research and Practice

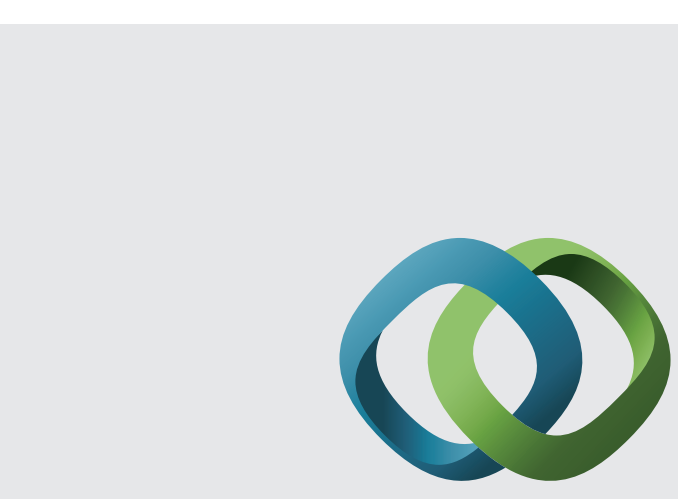

\section{Hindawi}

Submit your manuscripts at

http://www.hindawi.com
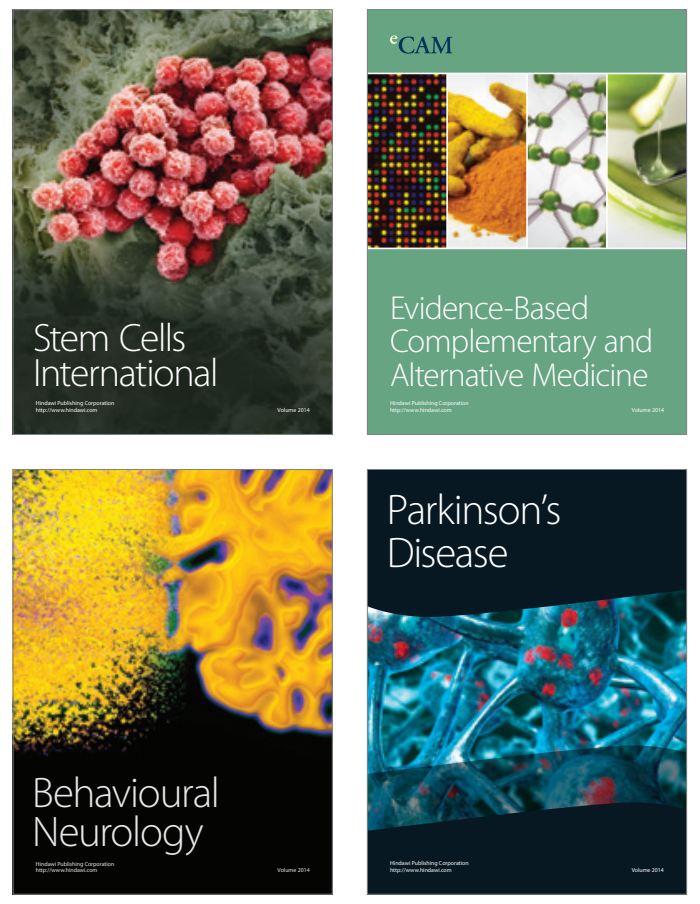
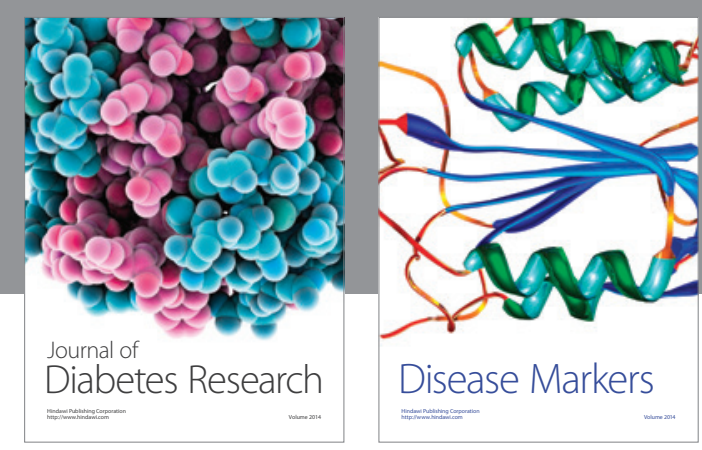

Disease Markers
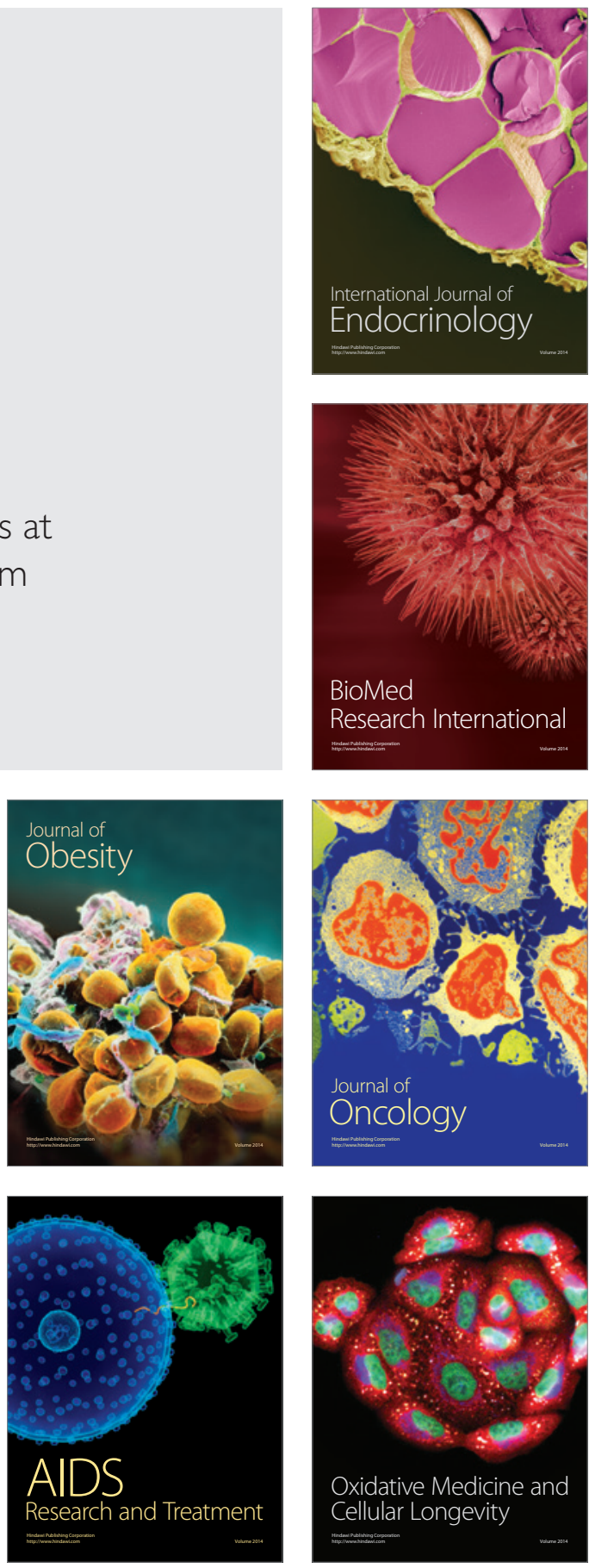